\title{
Cellulose nanocrystal reinforced acylglycerol-based polyurethane foams
}

\author{
M. V. Gangoiti ${ }^{1}$, P. J. Peruzzo ${ }^{2,3^{*}}$ \\ ${ }^{1}$ Laboratorio de Investigaciones en Osteopatías y Metabolismo Mineral - LIOMM (CIC-PBA), Facultad de Ciencias \\ Exactas - UNLP, 47 y 115, (B1900AJL) La Plata, Argentina \\ ${ }^{2}$ Instituto de Investigaciones Fisicoquímicas Teóricas y Aplicadas - INIFTA (UNLP - CONICET CCT La Plata), Diag. \\ 113 y 64, (B1904DPI) La Plata, Argentina. CC 16 Suc. 4 \\ ${ }^{3}$ Universidad Nacional Arturo Jauretche - UNAJ, Av. Calchaquí 6200, (1888) Florencio Varela, Argentina
}

Received 4 September 2019; accepted in revised form 25 November 2019

\begin{abstract}
This work presents the preparation of polyurethane composite foams based on castor oil or modified canola oil as a polyol, and cellulose nanocrystals $(\mathrm{CN})$ as nanofiller $(0.10,0.25$, and $0.50 \mathrm{wt} \%$ of $\mathrm{CN}$ content). The bio-based composites were characterized by Fourier Transform Infrared Spectroscopy (FTIR), Scanning Electron Microscopy (SEM), Differential Scanning Calorimetry (DSC), Thermogravimetric Analysis (TGA), and mechanical properties. The SEM images showed that composite foams had smaller cell sizes and more irregular than those observed for unloaded samples. FTIR revealed that the urethane/urea bond formation was influenced by the incorporation of $\mathrm{CN}$, and was dependent on the polyol used in the formulation. The incorporation of $\mathrm{CN}$ did not affect the thermal stability, but the density and mechanical properties changed differently depending on the selected polyol. These results suggested that the acylglycerol structure affects the role of $\mathrm{CN}$ in the formulation. Also, the proliferation of MC3T3-E1 preosteoblastic cells showed that the cell viability of polyurethane bionanocomposite foams increased significantly in comparison to the unloaded material.
\end{abstract}

Keywords: biocomposites, polyurethane biofoams, acylglycerol polyols, cellulose nanocrystal, cell viability

\section{Introduction}

Renewable resource-derived polymers and their composites have attracted attention in recent years due to increasing environmental concern and restricted availability of petrochemical resources. In this way, polyurethanes (PU) obtained by the incorporation of a bio-based substitute of the petrochemical raw materials have become an issue of interest [1]. PU are systems composed of soft (SS) and hard segments (HS), which are obtained from the polyol and isocyanate precursors, respectively. The chemical industry of PU has recently paid intense interest to the production of bio-based polyols, mainly those synthesized from vegetable oils [2], instead of the use of isocyanate precursors from renewable resources.
This is because isocyanates still depend on petroleum feedstocks, and research has not led to an industrially viable synthesis path [1]. Typically, castor oil and its derivatives are selected as polyols [3], but other oils like soybean oil and rapeseed oil have been used to a lesser extent after chemical modification to incorporate reactive hydroxyl groups in the structure $[4,5]$.

Within the wide variety of ways and forms in which PUs can be obtained, polyurethane foams (PUF) represent a relevant class of PU materials with several applications, ranging from insulation panels, structural reinforcement, and sandwich construction, among others like biomedical or electrical applications [6]. Bio-based PUF obtained from vegetable 
oil-based polyols have also been extensively studied, in particular from castor oil-based polyols. The works in this area reported that increases in the biopolyol content improve some properties of the final product like hydrophobicity (higher water contact angle, lower water uptake), and tensile modulus [7]. In PUF synthesized totally from vegetable oil-based polyols, the functionality and reactive group position affect the PU network, changing, in consequence, the cell structure and the mechanical and thermal properties of the final product $[8,9]$. Due to the hydrophobic nature of the vegetable oil-based polyols, they produced PUF with enhanced thermal stability, hydrophobicity, and hydrolytic stability. Although similar results were obtained for PUFs based on other vegetable oil-based polyols, they have not been extensively studied [10 12]. Despite the improvement of some properties of the biobased PUF as we described above, they are generally inferior when are compared to the properties of the petroleum-derived counterparts [13]. For this reason, it is common to prepare composites to cope with limitations such as low stiffness and low strength of PUF derived from vegetable oils $[14,15]$. The introduction of nanomaterials into polymeric composite foams has garnered much attention because nanofillers are proven able to affect the foam morphology, and can also change the mechanical/ rheological properties of the polymer matrix. Further, they could add additional functionality, such as electrical conductivity, thermal stability, and gas permeability [16]. Nanofillers such as glass fiber [14] clay [17, 18], silica [19], carbon fiber [20] and carbon nanotubes [21] have been used to enhance the mechanical properties and to confer new properties to the bio-based PUF composites. But the addition of nanofillers to PUF is also known to have variable effects depending on the percentage of loading and the size of particles [6,16], even more, if the filler changes the $\mathrm{NCO} / \mathrm{OH}$ ratio interfering on the rate of the foaming process. If the improvement of the properties is achieved by the incorporation of a filler, PUF composites can reduce the weight, energy, and cost of the material/application. Also, this strategy allows reducing the weight fraction of the hard segment and increasing as a consequence, the content of renewable component in the formulations. This is more favored if the nanoparticles are obtained from renewable resources. Thus, cellulose nanocrystals $(\mathrm{CN})$ have gained particular attention in recent years, not only for its unique physical and chemical properties but also for its inherent capacity for renewal and sustainability, in addition to its abundance [22].

The incorporation of $\mathrm{CN}$ to different polymer matrices has been extensively studied in the last years [23], and PUF was no exception [24, 25]. However, few studies of PUF obtained totally from vegetable oilbased polyols, and reinforced with $\mathrm{CN}$ have been published so far [26-30]. These works showed that CN incorporation affected the cell size, mechanical properties, dimensional stability, and water uptake of the foams. On the other hand, the addition of $\mathrm{CNs}$ decreased the thermal stability of PUF $[28,29]$. Because these works are based on different raw materials, it is difficult to obtain a general structure-property relationship of these foams. But they demonstrated that $\mathrm{CN}$ acted as reactive reinforcing filler, as well as nucleation agent and/or particulate surfactant depending on the Isocyanate index and the NCO number of the isocyanate $[27,28]$, affecting as a consequence the properties. In this way, the effect of changing the polyol on the role of $\mathrm{CN}$ in the formulation has not been taken into account. For polyols chemically similar, structural differences between them could affect the role of $\mathrm{CN}$ in the formulation. As a consequence, properties of the PUF could vary differently with the $\mathrm{CN}$ incorporation depending on the selected polyol. Therefore, the present work deals with the preparation of biocomposite PUF based on castor oil (CO) or modified canola oil (CanP) as polyol, and cellulose nanocrystals $(\mathrm{CN})$ as nanofiller. They were characterized by FTIR, SEM, TGA and mechanical properties. Because many works claim that these materials have potential applications in the field of biomedical engineering, cell viability was also evaluated.

\section{Experimental section}

\subsection{Materials}

Castor Oil (CO, Anedra 99.9\%, Argentina) was used as polyol, with $\mathrm{N}^{\circ} \mathrm{OH}=164.3 \mathrm{mg} \mathrm{KOH} / \mathrm{g}$ and acidity value of $0.8 \mathrm{mg} \mathrm{KOH} / \mathrm{g}$ (approx. functionality 2.7) determined according to ASTM D4274-99 (Test Method A). Canola Oil (CanO, Amerika 2001, Argentina), Formic Acid 85\% (Anedra, Argentina), $\mathrm{H}_{2} \mathrm{O}_{2} 30 \%$ (Biopack, Argentina); $\mathrm{HBF}_{4}$ (Merck, Germany); $\mathrm{MeOH}$ (Cicarelli, Argentina), Dibutyltindilaurate (DBTDL, 95\%, Sigma-Aldrich, U.S.A.) were used as received. Poly(methylene diphenyldiisocyanate) (pMDI, Suprasec 9634, Huntsman, U.S.A.), with a functionality of 2.15 and an NCO number of 


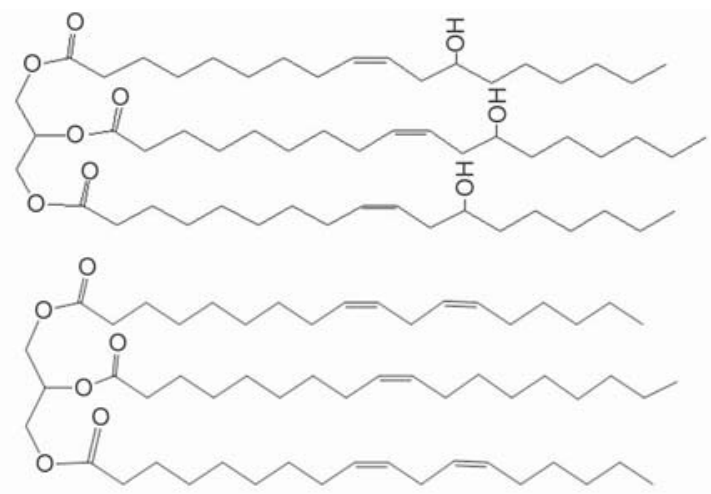

Figure 1. Idealized chemical structures of castor oil (above) and canola oil (down).

29.5 (determined according to ASTM D2572-97) was provided by Química R\&F S.R.L. (C.A.B.A., Argentina), and silicone-based surfactant (TEGOSTAB8409, Evonik, Germany) and the catalyst (TEGOAMIN41, Evonik, Germany) were kindly provided by Mayerhofer Argentina S.A. (C.A.B.A., Argentina). Distilled water was used as the blowing agent. The commercial $\mathrm{CN}$ was provided by the University of Mayne, which are rod-shaped particles of about $7 \mathrm{~nm}$ in diameter and $160 \mathrm{~nm}$ in length [31, 32]. Chemical structures of vegetable oils are presented in Figure 1.

\subsection{Preparation of canola based polyol}

Canola oil (CanO) was epoxidized using performic acid generated in situ, adapted from different techniques $[5,33]$. Formic acid $(16.40 \mathrm{ml})$ was added on canola oil (107.33 g), and the mixture was cooled in an ice-water bath. Then, hydrogen peroxide $(110.00 \mathrm{ml})$ was added drop by drop, and the reaction mixture was placed at $30^{\circ} \mathrm{C}$ for $24 \mathrm{~h}$ under mechanical stirrer. Later, the organic phase was washed twice with water, $\mathrm{NaHCO}_{3}$ saturated solution $(2 \times 30 \mathrm{ml})$, and water until neutral $\mathrm{pH}$. After drying, different from the other techniques, the epoxidized canola oil (ECO) was crystallized from solution at low temperature. Thus, materials present in the natural oil which did not react o were chemically different from the product remained in solution. The solid was filtered and dried until constant weight (61.88 g). To obtain a polyol by the ring-opening reaction of the epoxide group, the dried ECO $(60.00 \mathrm{~g})$ was added to a solution of $\mathrm{MeOH}(80.00 \mathrm{ml})$ and $\mathrm{HBF}_{4}(1.20 \mathrm{ml})$. The reaction mixture was mechanically stirred at $60^{\circ} \mathrm{C}$ for $3 \mathrm{~h}$. Finally, $100 \mathrm{ml}$ of ethyl acetate was added, and the organic layer was washed with water, then with $\mathrm{NaHCO}_{3}$ and brine, dried with

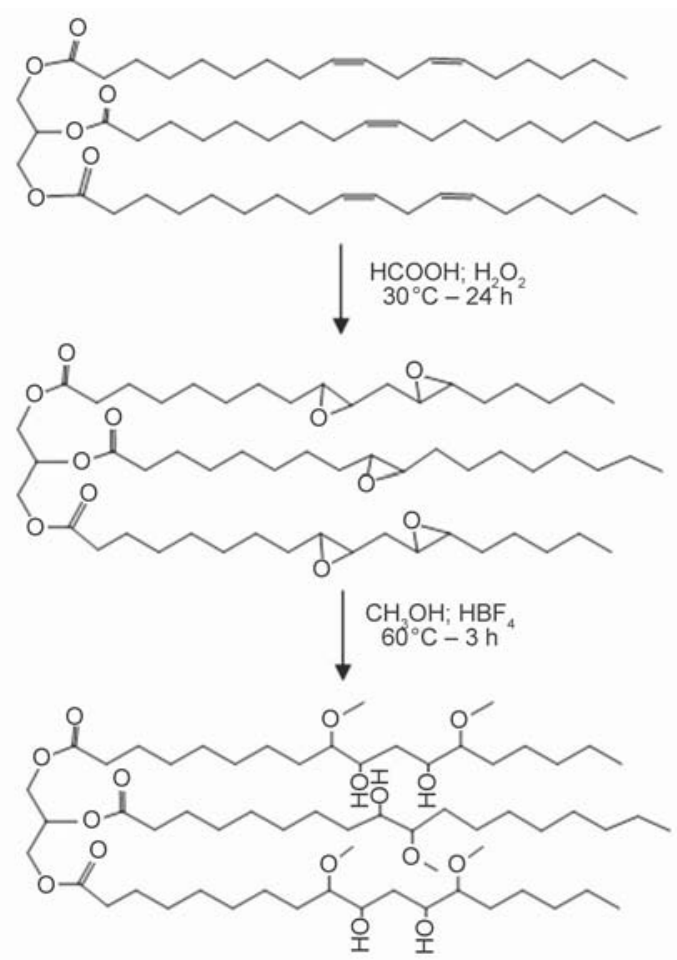

Figure 2. Scheme of synthesis of canola polyol (CanP).

anhydrous $\mathrm{Na}_{2} \mathrm{SO}_{4}$, filtered, and finally concentrated using a rotary evaporator. This produced a light yellow transparent oily product, coded as Canola polyol 'CanP' (57.60 g), with a hydroxyl value of $183.8 \mathrm{mg}$ $\mathrm{KOH} / \mathrm{g}$ (approx. functionality 3.3 ) and acidity value of $0.2 \mathrm{mg} \mathrm{KOH} / \mathrm{g}$ determined by ASTM D4274-99 (Test Method A). The scheme of reaction and FTIR characterization of products are shown in Figures 2 and 3 , respectively. In the canola oil spectrum, it was possible to observe the signals at $3006 \mathrm{~cm}^{-1}\left(\mathrm{v}_{\mathrm{C}-\mathrm{H}}\right)$ and $1652 \mathrm{~cm}^{-1}\left(v_{\mathrm{C}=\mathrm{C}}\right)$ related to the presence of double bonds in the canola oil. After epoxidation, the spectrum of the product (epoxidized canola oil) showed the peak related to the presence of the epoxy

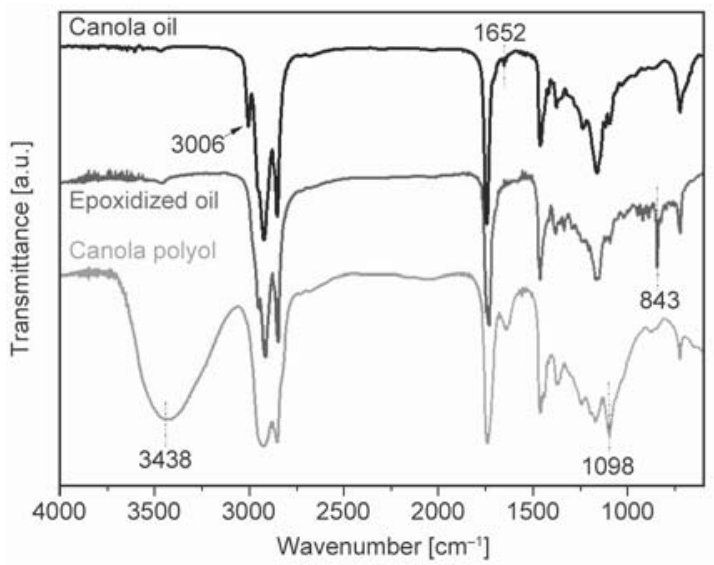

Figure 3. FTIR spectra of canola oil, epoxidized canola oil and canola polyol (CanP). 
groups at $843 \mathrm{~cm}^{-1}$ without evidence of $v_{=\mathrm{C}-\mathrm{H}}$ and $v_{\mathrm{C}=\mathrm{C}}$ signals. After polyol formation by reaction with methanol, new bands at $3438 \mathrm{~cm}^{-1}\left(v_{\mathrm{O}-\mathrm{H}}\right)$ and $1098 \mathrm{~cm}^{-1}\left(v_{\mathrm{C}-\mathrm{O}-\mathrm{C}}\right)$ were observed, while any band related to the epoxy ring was observed $[34,35]$.

\subsection{Foams preparation}

The foams were prepared by free-rising in a mold at room temperature [29]. First, the polyol, catalysts, surfactant and blowing agent were mixed for $30 \mathrm{~s}$ under mechanical stirring in a plastic beaker. After that, $\mathrm{CN}$ was added and mixed for $2 \mathrm{~min}$. When the mixture became homogeneous, pMDI was added and vigorously stirred for $20 \mathrm{~s}$, and then the foaming began after a short time. Finally, white, semi-rigid foam was obtained within a few seconds. Neat polyurethane foams were prepared using a similar foaming process in the absence of $\mathrm{CN}$. The foam was removed from the foaming beaker after $1 \mathrm{~h}$ and allowed to post-cure at room temperature for 1 week before the characterization. The formulations used are shown in Table 1, where the parts of each component are based on per hundred parts of the polyol, designated as php. A shorthand notation was used in this work where, for instance, CanP- 0.25 represents a nanocomposite polyurethane foam based on canola polyol containing $0.25 \mathrm{wt} \%$ of $\mathrm{CN}$.

\subsection{Characterization}

Apparent density was calculated as the ratio between the weight and the volume of a cubic specimen (25 mm side). At least five replicated specimens of each sample were measured.

FTIR spectra of samples were obtained using a IRAffinity-1 spectrophotometer (SHIMADZU CORPORATION, Japan) in DRIFT mode (64 scans for

Table 1. The recipe used in this work.

\begin{tabular}{|l|l|c|c|}
\hline \multicolumn{1}{|c|}{ Component } & \multicolumn{1}{|c|}{ Role } & $\begin{array}{c}\text { Castor oil } \\
\text { [php] }\end{array}$ & $\begin{array}{c}\text { Canola polyol } \\
\text { [php] }\end{array}$ \\
\hline \multicolumn{4}{|c|}{ Part A } \\
\hline CO or CanP & polyol & 100 & 100 \\
\hline TEGOSTAB8409 & surfactant & 2 & 2 \\
\hline TEGOAMIN41 & catalyst & 0.5 & 0.5 \\
\hline DBTDL & catalyst & 0.5 & 0.5 \\
\hline WATER & blowing agent & 3 & 3 \\
\hline CN & reinforcement & $0 ; 0.2 ; 0.5 ; 1$ & $0 ; 0.2 ; 0.5 ; 1$ \\
\hline \multicolumn{4}{|c|}{ Part B } \\
\hline pMDI & isocyanate & 93.6 & 98.8 \\
\hline
\end{tabular}

A/B index: $\sim 1.1$

Isocinate Index: 105 experiment and a resolution of $4 \mathrm{~cm}^{-1}$ ). For comparison, the characteristic absorbances were normalized using the $\mathrm{C}-\mathrm{H}$ absorbance at $2935 \mathrm{~cm}^{-1}$ as the standard.

The morphology of the cross-section of the foams was observed by Scanning Electron Microscopy (SEM) using a Jeol JSM-6460 microscope (JEOL Ltd, Japan). The samples were sputtered with a AuPd mixture before observation.

Thermogravimetric analysis (TGA) was obtained using a TA Q2000 instrument (TA, U.S.A.) running about $5 \mathrm{mg}$ sample from room temperature to $60^{\circ} \mathrm{C}$ at a heating rate of $10^{\circ} \mathrm{C} \cdot \mathrm{min}^{-1}$ in $\mathrm{N}_{2}$ atmosphere.

The compression properties of the films were measured at $25^{\circ} \mathrm{C}$ using a DIGIMESS TC-500 tensiletesting machine (DIGIMESS, Argentina). Specimens of $4 \mathrm{~cm}$ width and $4 \mathrm{~cm}$ length and $1 \mathrm{~cm}$ tall were prepared, and a testing speed of $5 \mathrm{~mm} \cdot \mathrm{min}^{-1}$ was used until $40 \%$ of deformation. The results were the average of five valid measurements.

For cytotoxicity assays, MC3T3-E1, a line of preosteoblastic cells, were used. Cells were maintained in basal media (DMEM-10\% FBS) at $37^{\circ} \mathrm{C}$. Cell proliferation was evaluated by the 3-(4,5-dimethylthiazol-2-yl)-2,5-diphenyl tetrazolium bromide (MTT) assay. MTT is converted to water-insoluble, dark blue MTT-formazan by mitochondrial dehydrogenases of living cells. Thus, absorbance change is directly proportional to the number of viable cells. Briefly, $2.5 \cdot 10^{4}$ cells per well in basal media were plated onto the scaffolds, which were cast on multiwell culture plates and cultured for 24 hours. After these culture periods, cells were incubated for two additional hours with a solution of $0.1 \mathrm{mg} \cdot \mathrm{ml}^{-1}$ MTT. Passed this time, stained cells were observed using a Nikon Eclipse TS100 inverted optical microscope (Nikon, Japan) and photographed. Then, after washing, the formazan precipitate was dissolved in dimethyl sulfoxide (DMSO), and the absorbance read at $570 \mathrm{~nm}$.

\section{Results and discussion}

\subsection{Foaming process}

Both polyols used in this works are acylglycerols with secondary $-\mathrm{OH}$ groups and similar dangling chain length, but they are different in functionality and the access to the $-\mathrm{OH}$ group. In $\mathrm{CanP}$ there are neighboring $\mathrm{CH}_{3} \mathrm{O}$ - groups that cause steric hindrance to the $-\mathrm{OH}$ reactive group; instead a cis double bond is present near to the- $-\mathrm{OH}$ group in the fatty 
Table 2. Foam behavior parameters $\left(t_{\mathrm{c}}\right.$ : cream time; $t_{\mathrm{r}}$ : end of rise time; $t_{\mathrm{t}}$ : tack-free time) of foams obtained in this work.

\begin{tabular}{|l|c|c|c|c|c|c|}
\hline & \multicolumn{3}{|c|}{ Castor oil } & \multicolumn{3}{c|}{ Canola polyol } \\
\hline \multirow{2}{*}{ CN content } & $\begin{array}{c}\boldsymbol{t}_{\mathbf{c}} \\
{[\mathbf{s}]}\end{array}$ & $\begin{array}{c}\boldsymbol{t}_{\mathbf{r}} \\
{[\mathbf{s}]}\end{array}$ & $\begin{array}{c}\boldsymbol{t}_{\boldsymbol{t}} \\
{[\mathbf{s}]}\end{array}$ & $\begin{array}{c}\boldsymbol{t}_{\mathbf{c}} \\
{[\mathbf{s}]}\end{array}$ & $\begin{array}{c}\boldsymbol{t}_{\mathbf{r}} \\
{[\mathbf{s}]}\end{array}$ & $\begin{array}{c}\boldsymbol{t}_{\mathbf{t}} \\
{[\mathbf{s}]}\end{array}$ \\
\hline 0 & $10 \pm 2$ & $42 \pm 4$ & $50 \pm 4$ & $34 \pm 2$ & $90 \pm 5$ & $170 \pm 8$ \\
\hline 0.1 & $9 \pm 3$ & $40 \pm 3$ & $50 \pm 3$ & $30 \pm 2$ & $103 \pm 3$ & $180 \pm 9$ \\
\hline 0.25 & $9 \pm 2$ & $41 \pm 3$ & $51 \pm 3$ & $34 \pm 2$ & $108 \pm 4$ & $185 \pm 6$ \\
\hline 0.5 & $8 \pm 2$ & $40 \pm 3$ & $50 \pm 5$ & $32 \pm 3$ & $102 \pm 5$ & $180 \pm 8$ \\
\hline
\end{tabular}

acid chains of CO. Table 2 shows the foaming behavior of the samples obtained in this work. The cream time $\left(t_{\mathrm{c}}\right)$, end of rise time $\left(t_{\mathrm{r}}\right)$ and tack-free time $\left(t_{\mathrm{t}}\right)$ were higher for CanP-based PUF comparing to CO-based samples. This can be attributed to the more sterically hindered $-\mathrm{OH}$ groups in the CanP polyol due to the neighboring $-\mathrm{OCH}_{3}$ groups, which affect the reactivity and consequently the rate of expansion and gelation time [29, 36]. For each series (CO or CanP), tc, tr and tt were similar for composite samples with different $\mathrm{CN}$ content. However, tr and tt slightly increased for the composite samples based on CanP polyol respect to the CanP-0 sample. This indicated that the incorporation of the $\mathrm{CN}$ did not affect significantly foaming behavior when $\mathrm{CO}$ is used in the formulation [29], but had an impact in the case of CanP.

\subsection{FTIR results}

Figure 4a shows the FTIR spectra of $\mathrm{CN}$ and PUF without and with $0.5 \mathrm{wt} \%$ of CN. The PU spectrum showed the typical band at around $3335 \mathrm{~cm}^{-1}$ arising from $v_{\mathrm{N}-\mathrm{H}}$ mode (free and H-bonded), an absorption at $1720 \mathrm{~cm}^{-1}$ related to the PU Amide I band ( $v_{\mathrm{C}=\mathrm{O}}$ in urethane bond) overlapped to $v_{\mathrm{C}=\mathrm{O}}$ of -COO- groups present in natural polyols, and a band centered at $1557 \mathrm{~cm}^{-1}$ (Amide II band, $\delta_{\mathrm{N}-\mathrm{H}}+v_{\mathrm{C}-\mathrm{N}}+v_{\mathrm{C}-\mathrm{C})}$. For the pure $\mathrm{CN}$ the band between 3600 and $3200 \mathrm{~cm}^{-1}$ was related to the $\mathrm{O}-\mathrm{H}$ stretching vibrations, and the absorption bands between 300-2800 and $1500-1250 \mathrm{~cm}^{-1}$ regions came from the $\mathrm{C}-\mathrm{H}$ and $\mathrm{C}-\mathrm{H}_{2}$ stretching and bending vibrations, respectively. Besides, it was also possible to observe the band related to the glycosidic linkage $\left(1155 \mathrm{~cm}^{-1}\right)$ and the strongest band located between $1100-970 \mathrm{~cm}^{-1}$ dominated by ring vibrations overlapped with stretching vibrations of $\mathrm{C}-\mathrm{OH}$ side groups, and at $1029 \mathrm{~cm}^{-1}$ the $\mathrm{C}-\mathrm{O}-\mathrm{C}$ stretching in the pyranoid ring [37, 38]. Incorporating $\mathrm{CN}$ did not introduce changes in the intensity of the regions
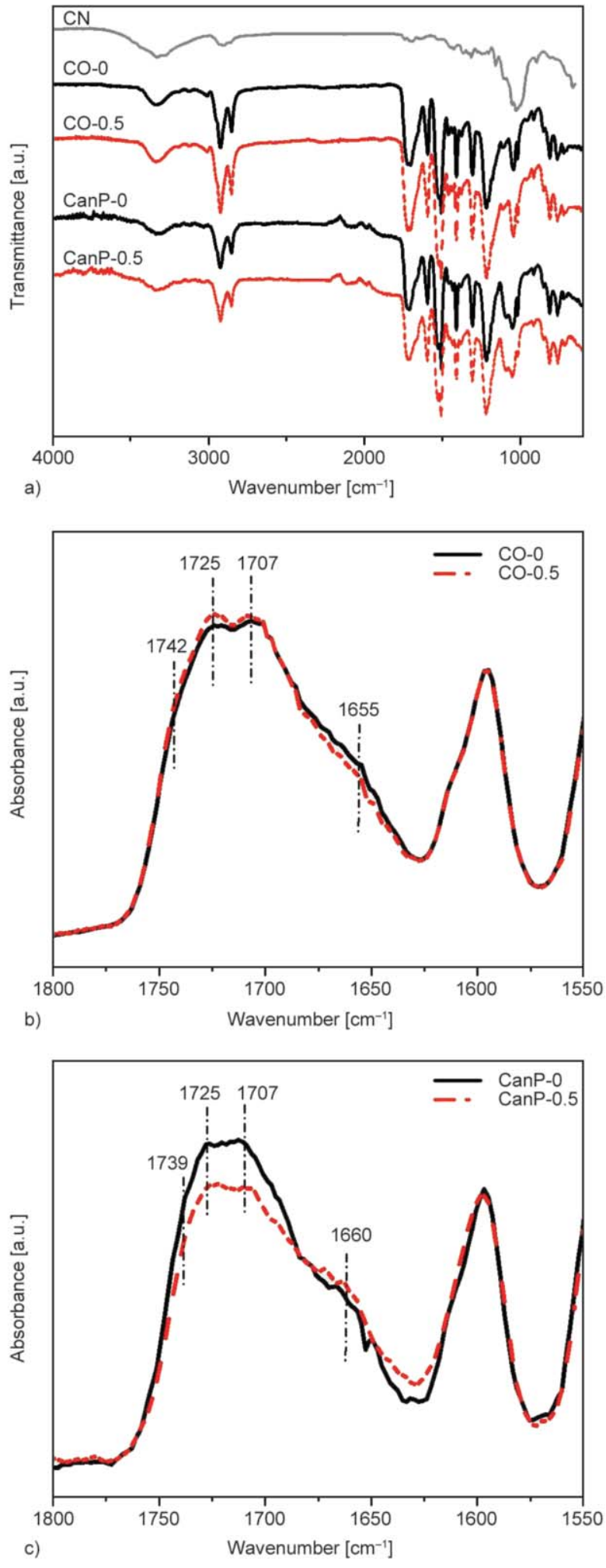

Figure 4. a) FTIR spectra of CN, PUF, and nanocomposites PUF containing $0.5 \mathrm{wt} \%$ of $\mathrm{CN}$. b) Carbonyl region for samples CO-0 and CO-0.5; c) Carbonyl region for samples CanP-0 and CanP-0.5.

around 1100 or $3300 \mathrm{~cm}^{-1}(\mathrm{C}-\mathrm{O}-\mathrm{C}$ and $\mathrm{O}-\mathrm{H}$ in $\mathrm{CN}$, respectively) due to the lower $\mathrm{CN}$ content of the samples of this work [27]. Instead, changes were 
observed in the $\mathrm{C}=\mathrm{O}$ region. When this region was observed in detail (Figure $4 \mathrm{~b}$ and $4 \mathrm{c}$ ), it was possible to detect the contribution of the carbonyl stretching vibration of $\mathrm{C}=\mathrm{O}$ groups belonging to the ester groups present in the triglycerides at around $1740 \mathrm{~cm}^{-1}$ [39], the signals at $1725 \mathrm{~cm}^{-1}$ and $1701 \mathrm{~cm}^{-1}$ related to free and $\mathrm{H}$-bonded $v_{\mathrm{C}=\mathrm{O}}$ of the urethane linkage, respectively, and the band located at $1650 \mathrm{~cm}^{-1}$ assigned to the $v_{\mathrm{C}=\mathrm{O}}$ in urea bonds. In the case of CO-based samples, a slight decrease in the formation of urea bonds and the formation of additional urethane linkages were observed with the incorporation of $\mathrm{CN}$ (Figure $4 b$ ), suggesting that $-\mathrm{NCO}$ groups reacted with the hydroxyl groups at the $\mathrm{CN}$ surface changing the internal organization of the PU matrix. Instead, a noticeable decrease in the relative amount of urethane groups in the CanP based foams containing $\mathrm{CN}$ was detected, indicating that $\mathrm{CN}$ interacts with the SS when this polyol is used in the formulation. This would lead to a reduction in the availability of - $\mathrm{OH}$ groups of both materials preventing the formation of urethane groups. These results are in agreement with that observed by other authors [28], suggesting in this case that incorporating $\mathrm{CN}$ modified the urethane and urea kinetics. However, they changed in a different way depending on the polyol used in the formulation, in accordance with the foaming behavior previously presented.

\subsection{SEM results}

Optical and SEM images of the prepared foams are shown in Figure 5. PUF and composites obtained from $\mathrm{CO}$ are light-yellow comparing to those obtained from CanP, which were whiter foam and with larger cell size. Besides, CO-based samples were closed cell foams, whereas open-cell foams were obtained from CanP. Incorporating $\mathrm{CN}$ resulted in foams with smaller cell sizes and anisotropic, having a larger dimension parallel to the growth direction (Figure $5 \mathrm{c}$ and $5 \mathrm{~d}$ ). Table 3 shows the cell dimensions on the direction parallel $(L)$ and perpendicular $(T)$ to the growth direction, and the anisotropic factor $(r=L / T)$, which resulted similar for all the nanocomposite foams independently of both the polyol and $\mathrm{CN}$ content. The fact that CanP- 0.1 presented cell dimensions between CanP-0 and CanP-0.25 suggested that polyol characteristics seem to have an effect on the cell dimensions of the nanocomposite foams at lower $\mathrm{CN}$ content. However, cell size was similar when $\mathrm{CN}$ content higher than $0.25 \mathrm{wt} \%$ was used, regardless of the selected polyol. Thus, the addition of $\mathrm{CN}$ decreased the cell dimensions for both series ( $\mathrm{CO}$ and $\mathrm{CanP}$ ) suggesting that $\mathrm{CN}$ provides sites which facilitate the nucleation process [27], with opposite effect on the density of the foams (as can be observed in the next section) depending on the polyol used in the formulation.

\subsection{Properties of foams}

Reference PUF samples (CO-0 and CanP-0) presented density values of 51 and $59 \mathrm{~kg} \cdot \mathrm{m}^{-3}$, respectively, where the difference can be explained based on the polyol properties ( $\mathrm{OH}$ - functionality). When density values of the nanocomposite foams were observed, samples obtained from $\mathrm{CO}$ showed higher density comparing to the reference sample $\mathrm{CO}-0$, while composite samples based on CanP presented a lower density than the unloaded material. The results are in agreement with the FTIR observations, where the decrease in the formation of urea bonds in the CObased composite foams could be associated with a lower blowing gas production, and consequently, higher density was obtained for these samples. In the case of CanP-based composite foams, a lower urethane bond production avoids the formation of the polymer matrix and consequently the density decreases. Thus, the addition of $\mathrm{CN}$ changed the growth stage in a different way depending on the polyol used, but independently of the $\mathrm{CN}$ content for the formulation used in this work.

The results of the compression tests, compressive elastic modulus $(E)$, and strength $(\sigma)$ are presented in Table 4. In general, the incorporation of the nanofiller improved the mechanical properties of PUFs. In both series ( $\mathrm{CO}$ and $\mathrm{CanP}$ based samples) an increase of the compressive modulus $E$ was observed for all the samples regardless of $\mathrm{CN}$ content. However, the compressive strength $\sigma$ of the PUFs based on $\mathrm{CO}$ increased as $\mathrm{CN}$ content increases, while the biobased foams based on CanP maintained a similar value of $\sigma$ regardless of the $\mathrm{CN}$ content. These observations were maintained indeed when density was taken into account to obtain the specific strength $(\sigma / d)$ and specific modulus $(E / d)$ (Table 4$)$. The specific strength of CanP based composites increases by about $10 \%$, independently of the $\mathrm{CN}$ content. Instead, in CO-based composites, the specific strength increases gradually up to $300 \%$ for CO- 0.5 sample, in agreement with the participation of $\mathrm{CN}$ as HS in the formation of the polymeric matrix. Indeed, while 

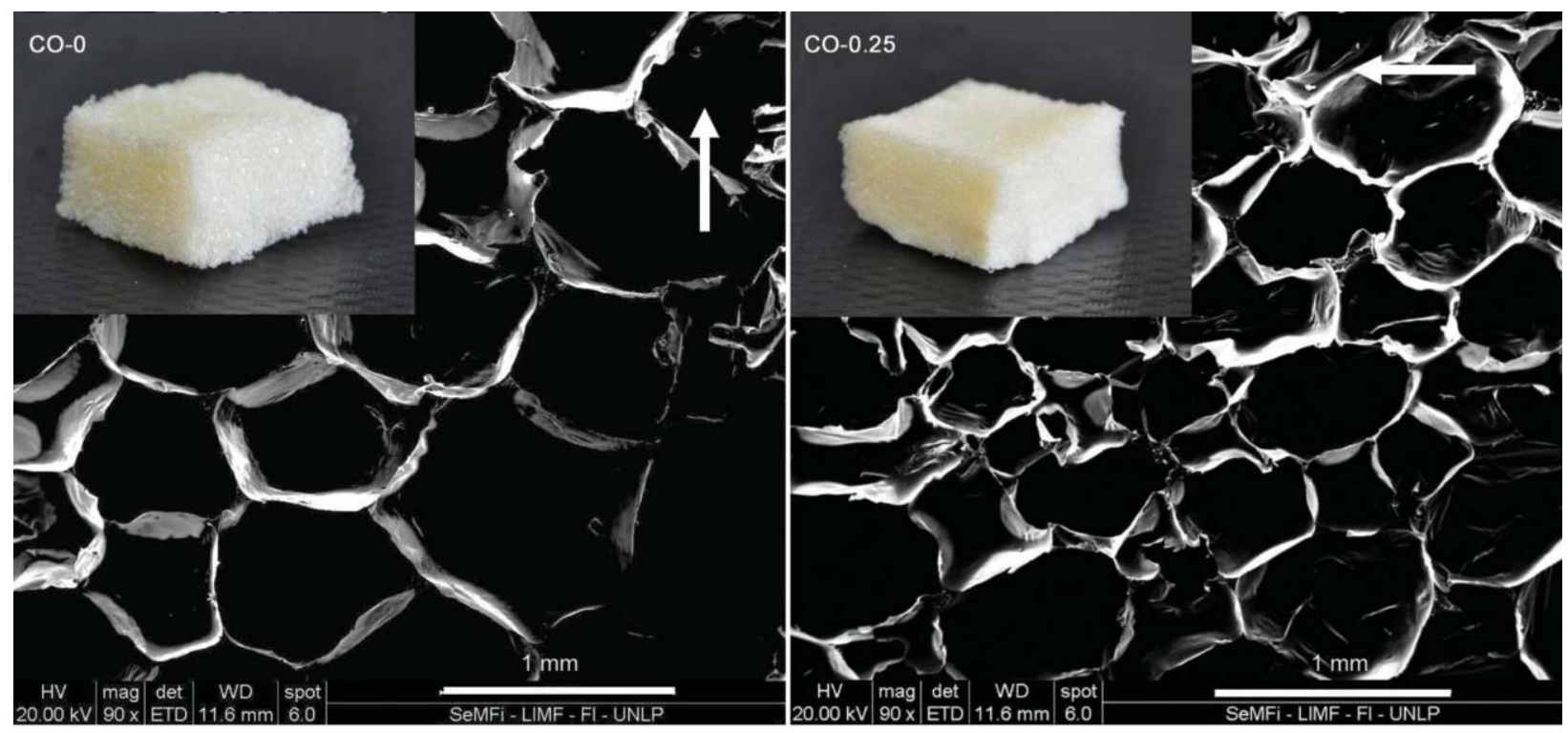

a)

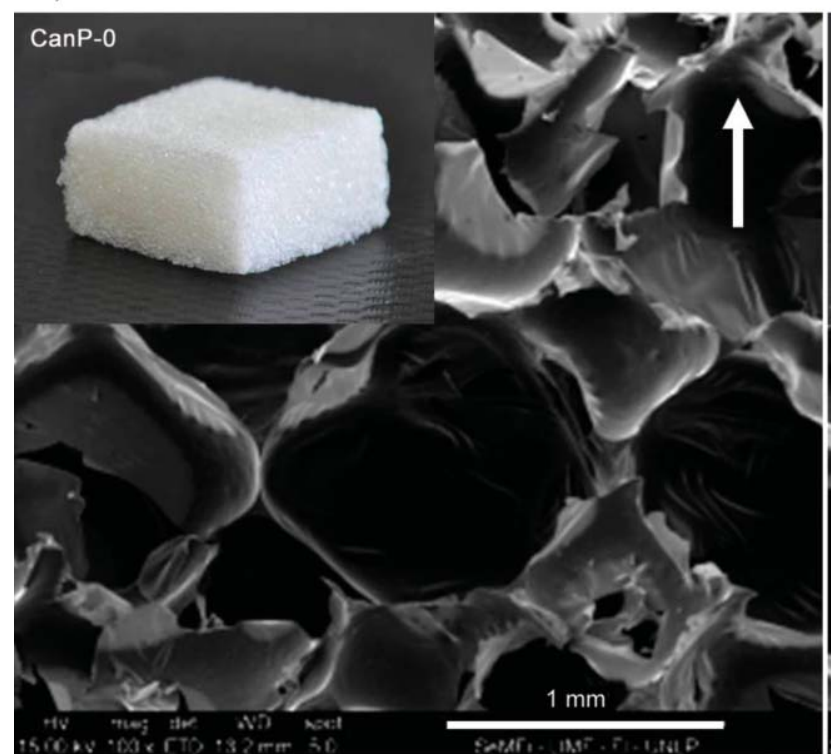

b)

c)

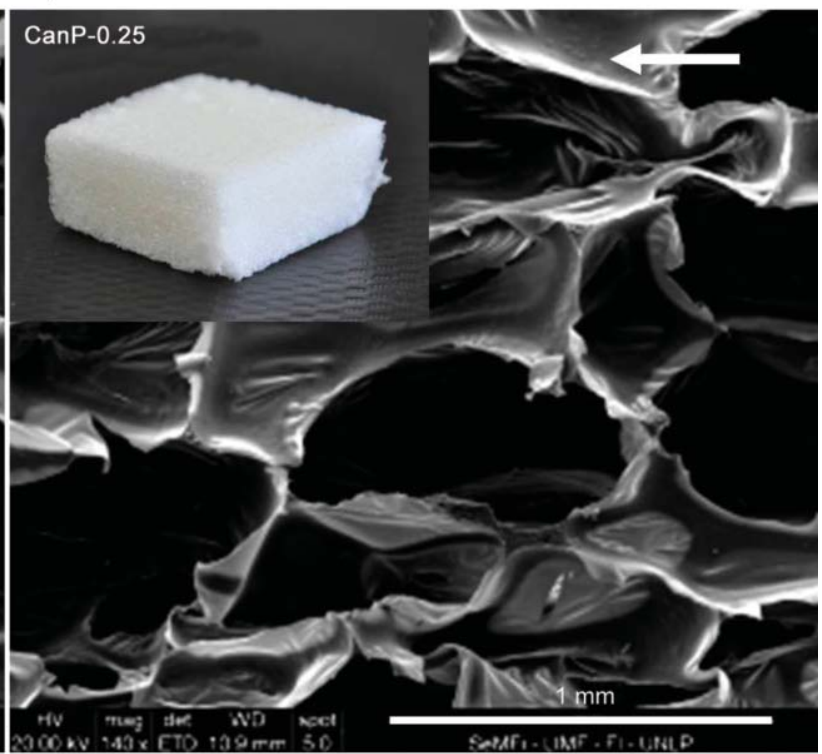

d)

Figure 5. Optical and SEM images of polyurethane foams and nanocomposite PUF with 0.25 wt.\% CN content. Arrows indicate the PUF growth direction. a) CO-0 sample; b) CO-0.25 sample; c) CanP-0 sample; and d) CanP-0.25 sample.

Table 3. Cell dimensions of PUFs obtained in this work.

\begin{tabular}{|c|c|c|c|c|c|c|c|c|}
\hline & \multicolumn{4}{|c|}{ Castor oil } & \multicolumn{4}{|c|}{ Canola polyol } \\
\hline & \multicolumn{4}{|c|}{$\begin{array}{c}\text { CN content } \\
{[w t \%]}\end{array}$} & \multicolumn{4}{|c|}{$\begin{array}{c}\text { CN content } \\
{[w t \%]}\end{array}$} \\
\hline & $\mathbf{0}$ & 0.1 & 0.25 & 0.5 & $\mathbf{0}$ & 0.1 & 0.25 & 0.5 \\
\hline $\begin{array}{ll}L & {[\mathrm{~mm}]}\end{array}$ & $0.70 \pm 0.16$ & $0.71 \pm 0.11$ & $0.70 \pm 0.14$ & $0.68 \pm 0.17$ & $0.92 \pm 0.14$ & $1.09 \pm 0.20$ & $0.76 \pm 0.18$ & $0.79 \pm 0.15$ \\
\hline $\begin{array}{ll}T & {[\mathrm{~mm}]}\end{array}$ & $0.78 \pm 0.16$ & $0.43 \pm 0.08$ & $0.37 \pm 0.07$ & $0.43 \pm 0.10$ & $0.87 \pm 0.15$ & $0.63 \pm 0.18$ & $0.45 \pm 0.14$ & $0.46 \pm 0.10$ \\
\hline$r=L / T$ & 0.90 & 1.66 & 1.89 & 1.58 & 1.06 & 1.73 & 1.70 & 1.72 \\
\hline
\end{tabular}

$L$ : cell dimension in the growth direction, $T$ : cell dimension in the perpendicular growth direction

specific modulus increase as $\mathrm{CN}$ content increase for $\mathrm{CO}$ based samples, higher amounts $\mathrm{CN}$ seems to be detrimental to this parameter in the CanP series. This is probably due to the interaction of the filler with the SS and, as a consequence a lower urethane linkage formation in agreement with FTIR results.

Plots from TGA and dTGA of CN, PUFs, and nanocomposite foams containing $0.25 \mathrm{wt} \%$ of $\mathrm{CN}$ content 
Table 4. Density and mechanical properties of the BPU foams.

\begin{tabular}{|l|c|c|c|c|c|}
\hline \multicolumn{1}{|c|}{ Sample } & $\begin{array}{c}\boldsymbol{d} \\
{\left[\mathbf{k g} / \mathbf{m}^{\mathbf{3}}\right]}\end{array}$ & $\begin{array}{c}\boldsymbol{\sigma}_{\mathbf{1 0} \%} \\
{[\mathbf{k P a}]}\end{array}$ & $\begin{array}{c}\boldsymbol{\sigma}_{\mathbf{1 0} \%} / \boldsymbol{d} \\
{\left[\mathbf{k N} \cdot \mathbf{m} \cdot \mathbf{K} \cdot \mathbf{g}^{-\mathbf{1}}\right]}\end{array}$ & $\begin{array}{c}\boldsymbol{E} \\
{[\mathbf{k P a}]}\end{array}$ & $\begin{array}{c}\boldsymbol{E} / \boldsymbol{d} \\
{\left[\mathbf{k N} \cdot \mathbf{m} \cdot \mathbf{K} \cdot \mathbf{g}^{-\mathbf{1}}\right]}\end{array}$ \\
\hline CO-0 & $51 \pm 4$ & $10 \pm 1$ & 0.20 & $163 \pm 17$ & 3.20 \\
\hline CO-0.1 & $63 \pm 1$ & $22 \pm 5$ & 0.35 & $503 \pm 132$ & 7.99 \\
\hline CO-0.25 & $58 \pm 3$ & $38 \pm 5$ & 0.66 & $461 \pm 5$ & 7.95 \\
\hline CO-0.5 & $61 \pm 2$ & $51 \pm 11$ & 0.84 & $705 \pm 57$ & 11.56 \\
\hline CanP-0 & $59 \pm 4$ & $38 \pm 5$ & 0.64 & $182 \pm 11$ & 3.09 \\
\hline CanP-0.1 & $48 \pm 5$ & $35 \pm 4$ & 0.73 & $563 \pm 128$ & 11.74 \\
\hline CanP-0.25 & $51 \pm 3$ & $33 \pm 6$ & 0.65 & $624 \pm 142$ & 12.23 \\
\hline CanP-0.5 & $50 \pm 3$ & $36 \pm 6$ & 0.72 & $408 \pm 102$ & 8.17 \\
\hline
\end{tabular}

are shown in Figures $6 \mathrm{a}$ and $6 \mathrm{~b}$, respectively. Also, the IDT (initial decomposition temperature) and the thermal indexes $T_{5}$ and $T_{50}$ (temperatures corresponding to a $5 \%$ and $50 \%$ loss in weight) are shown in Table 5. TGA and dTGA curves of samples revealed noticeable differences in the whole temperature range depending on the polyol used in their synthesis. For CO-based samples, decomposition started at approximately $260^{\circ} \mathrm{C}$. On the other hand, samples based on CanP showed lower thermal stability, in which decomposition started at $220^{\circ} \mathrm{C}$, with lower $T_{5}$ and $T_{50}$ than PUFs based on CO. Besides, dTGA curves revealed different behavior for the different decomposition steps, related to differences in the structures of the polyol. In general, thermal decomposition profile of bio-based PUF has been reported maximum in the dTGA curves at temperatures around 230$330^{\circ} \mathrm{C}$ related to urethane bond decomposition [40], 350-390 ${ }^{\circ} \mathrm{C}$ attributed to ester/ether bond decomposition through chain scission $[41,42]$, and 430 $470{ }^{\circ} \mathrm{C}$ (due to $\mathrm{C}-\mathrm{C}$ bond cleavages [43]. In our case, dTGA curves of samples obtained from CO presented three decomposition steps, where the first peak at $309^{\circ} \mathrm{C}$ in dTGA curve showed a shoulder at lower temperature. Instead, the first decomposition process

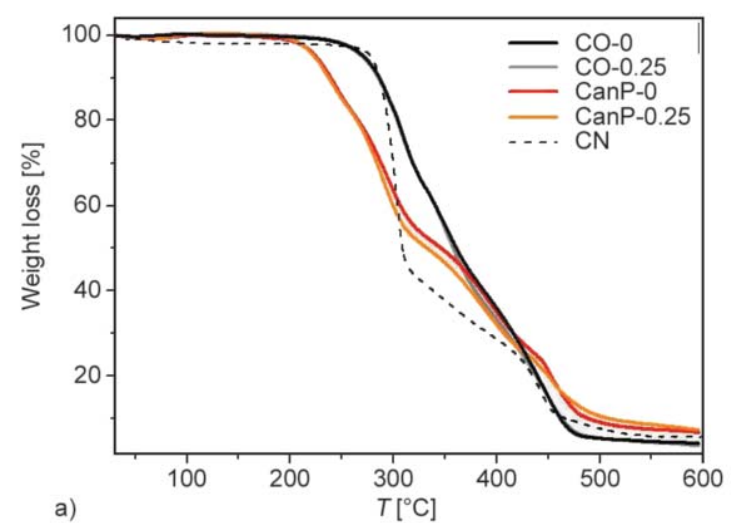

of CanP samples presented two peaks located at 244 and $295^{\circ} \mathrm{C}$ in the dTGA curve. This can be attributed to differences in the polymer network structures due to the different structure of the used polyols, where the secondary functional hydroxyl groups in the CanP are more sterically hindered and probably conduct to a low cross-linking density and less stable urethane bonds because they avoid the typical H-bonding organization of the PU $[5,8]$. Furthermore, differences in the polyol structures also influenced the second thermal decomposition steps, probably due to differences in the dangling chain length, number of unsaturations, and the presence of ether bonds depending the polyol selected for the foam synthesis [4, 8, 44-46]. Incorporating $\mathrm{CN}$ produced a slight decrease in the thermal stability of both systems. This change seems to be related to a contribution of the decomposition of the $\mathrm{CN}$ around $300^{\circ} \mathrm{C}$ (depolymerization, dehydration, and decomposition of glycosyl units) [47], and $440^{\circ} \mathrm{C}$ (oxidation and decomposition of carbonaceous residue to gaseous products of low molecular weight) [48].

The results suggested that $\mathrm{CN}$ has a different role depending on the acylglycerol used in the formulation. Previous works have demonstrated that the $\mathrm{CN}$ in a

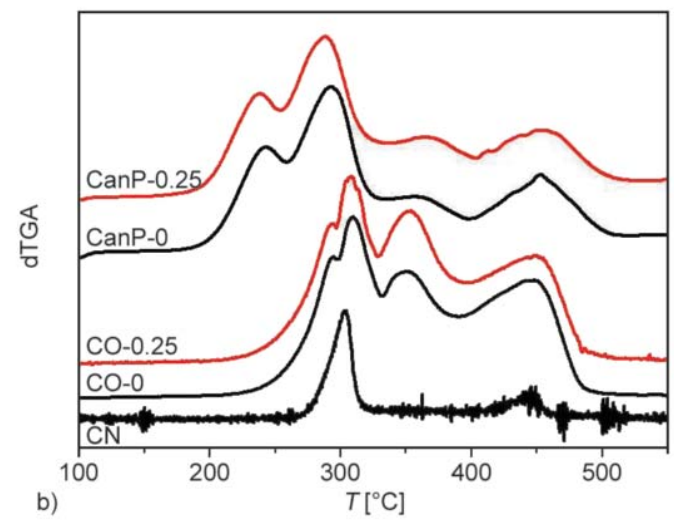

Figure 6. TGA (a) and dTGA (b) curves of selected samples obtained in this work. 
Table 5. Thermal properties of the BPU foams.

\begin{tabular}{|l|c|c|c|c|c|c|c|}
\hline \multirow{3}{*}{ Sample } & \multicolumn{9}{|c|}{$\mathbf{T G A}$} \\
\cline { 2 - 9 } & $\begin{array}{c}\text { ID } \\
{\left[{ }^{\circ} \mathbf{C}\right]}\end{array}$ & $\begin{array}{c}\boldsymbol{T}_{\mathbf{5}} \\
{\left[{ }^{\circ} \mathbf{C}\right]}\end{array}$ & $\begin{array}{c}\boldsymbol{T}_{\mathbf{5 0}} \\
{\left[{ }^{\circ} \mathbf{C}\right]}\end{array}$ & $\begin{array}{c}\boldsymbol{T d}_{\mathbf{1}} \\
{\left[{ }^{\circ} \mathbf{C}\right]}\end{array}$ & $\begin{array}{c}\boldsymbol{T}_{\mathbf{2}} \\
{\left[{ }^{\circ} \mathbf{C}\right]}\end{array}$ & $\begin{array}{c}\boldsymbol{T d}_{\mathbf{3}} \\
{\left[{ }^{\circ} \mathbf{C}\right]}\end{array}$ & $\begin{array}{c}\boldsymbol{T d}_{\mathbf{4}} \\
{\left[{ }^{\circ} \mathbf{C}\right]}\end{array}$ \\
\hline CO-0 & 265.40 & 271.43 & 360.94 & $294.98^{\mathrm{a}}$ & 309.27 & 351.15 & 447.85 \\
\hline CO-0.1 & 260.53 & 265.03 & 354.01 & $292.90^{\mathrm{a}}$ & 305.92 & 352.31 & 449.52 \\
\hline CO-0.25 & 265.58 & 269.83 & 356.68 & $292.85^{\mathrm{a}}$ & 307.27 & 352.34 & 448.46 \\
\hline CO-0.5 & 259.62 & 259.17 & 351.88 & $293.86^{\mathrm{a}}$ & 305.62 & 355.95 & 449.82 \\
\hline CanP-0 & 218.70 & 224.85 & 346.79 & 244.30 & 295.37 & 360.05 & 451.99 \\
\hline CanP-0.1 & 215.39 & 221.45 & 328.08 & 242.27 & 292.59 & 356.11 & 452.90 \\
\hline CanP-0.25 & 213.90 & 223.15 & 332.05 & 239.34 & 289.58 & 362.01 & 455.30 \\
\hline CanP-0.5 & 213.14 & 220.88 & 332.61 & 237.92 & 287.93 & 364.74 & 450.45 \\
\hline
\end{tabular}

${ }^{\text {a }}$ shoulder at peak with maximum at $T d_{2}$

PUF can associate to the HS or SS in the polyurethane network and acting as nucleation agent or particulate surfactant, depending on the isocyanate index and NCO number of the isocyanate formulation as previously exposed $[8,27,28]$. In our case, the experimental results suggested that the acylglycerolbased polyol used in the formulation of the PUF also affects this behavior, where $\mathrm{CN}$ acted as a nucleation agent, with a migration to the HS in the case of the CO-based polyurethane foams, and to the SS in CanP based samples.

\subsection{Cell viability}

Many works related to bio-based PU or PUF claim that these materials have potential applications in the field of biomedical engineering. Even if the constituents are bio-based and well biocompatible, the resulting material is not necessarily biocompatible. So, it is necessary to conduct tests before indicating if a bio-based material can be considered as a potential biocomposite product [49]. The in-vitro biocompatibility of the biofoams obtained in this work was evaluated by MTT assay (Figure 7a) and the observation of the cell morphology (Figure 7b). Figure 7a shows that the incorporation of $0.1 \mathrm{wt} \% \mathrm{CN}$ did not change the growth of cells. However, at concentrations of 0.25 and $0.5 \mathrm{wt} \%$ of CN both PUF-CO (Figure $7 \mathrm{a} / \alpha$ ) and PUF-CanP (Figure $7 \mathrm{a} / \beta$ ) increased significantly the MC3T3-E1 cells proliferation with respect to the control (PUF without $\mathrm{CN}$ ), being higher for samples based on $\mathrm{CO}$. The evaluation of cell morphology after $24 \mathrm{~h}$ showed that cells survived and grew on the different materials, as it can be observed in Figure $7 \mathrm{~b}$ for CanP-0 and CanP-0.25 samples as representative images. For samples without $\mathrm{CN}$, it seems that the cells preferred to adhere to each other rather than grow on the surface and spread.
However, for samples with 0.25 and $0.5 \mathrm{wt} \%$ of $\mathrm{CN}$ content, they were flattened on the surface with more spindle-like morphology, which was indicative that the cells proliferated and adhered strongly to the composite foams respect to the unloaded samples [50], these observations could be related to changes in the hydrophilicity of the materials due to the used polyol [51] and incorporation of CN [52]. Regardless of this, the obtained results were indicative of the improvement of the cell viability of the reinforced polyurethane foams at these $\mathrm{CN}$ concentrations.

\section{Conclusions}

This work presented the preparation of polyurethane biobased composite foams obtained from polymeric methylene diphenyl isocyanate, castor oil or modified canola oil as polyol, and different contents of cellulose nanocrystals. Polyurethane foams with a density of around $50-60 \mathrm{~kg} \cdot \mathrm{m}^{-3}$ were obtained. Incorporating $\mathrm{CN}$ they modified the morphology, leading to the production of foams with smaller cell sizes and more irregular than those observed for the matrix. Besides, improving the mechanical properties of the PU, biobased foams, without significant changes in thermal properties, were obtained. Taken as a whole, the variation of the properties with the incorporation of $\mathrm{CN}$ suggested that the chemical structure of the polyol affects the role played by $\mathrm{CN}$ in the formulation of the bio-based PUF. When CanP was used, the $\mathrm{CN}$ interacted better with the soft segment, which affected the urethane bond formation and resulted in a decrease in the foams' density, and a slight improvement in mechanical properties. This was different in the case of $\mathrm{CO}$, where $\mathrm{CN}$ took part in the urethane bond formation acting as a hard segment, with an increase of the composite foams' density and 

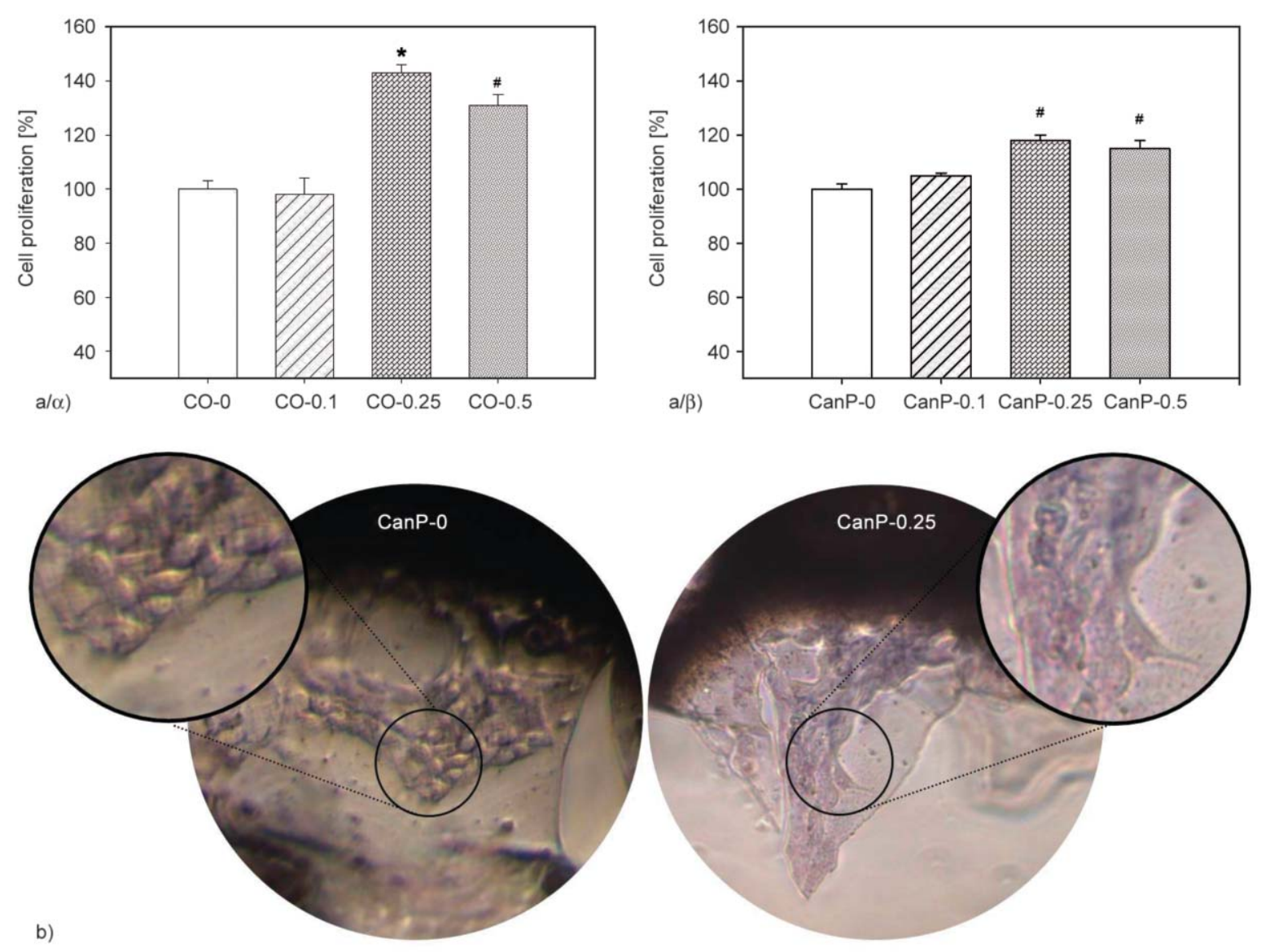

Figure 7. a) MC3T3-E1 cell proliferation using MTT assay on PUF based on CO ( $\alpha$ ) or PUF based on CanP (b). Values are expressed as \% versus PU after $24 \mathrm{~h}$ of proliferation. *: $p<0,01$; \#: $p<0,05$. b) Cell morphology of the MC3T3E1 cells grown on the foams CanP-0 and CanP-0.25 for $24 \mathrm{~h}$ of culturing.

an improvement of the mechanical properties. When evaluating the proliferation of cells grown on different foams, it was observed that the presence of $\mathrm{CN}$ significantly increased the cell viability for samples containing 0.25 and $0.50 \mathrm{wt} \%$ of $\mathrm{CN}$, while for the lowest concentration used no effect was observed. The results suggest that the incorporation of $\mathrm{CN}$ increases the biocompatibility of the PU foams, which place them as materials with potential biomedical applications.

\section{Acknowledgements}

This work was supported by the ANPCyT (PICT 20130643), UNAJ (project UNAJ Investiga 2014), and UNLP (PPID X028). We would like to thank Lidia Bruzza (Química R\&F S.R.L.) and Alejandro de Gasperi (Mayerhofer Argentina S.A.) for supplying the reactants. MVG is a member of CIC-PBA and PJP is a member of CONICET.

\section{References}

[1] Nohra B., Candy L., Blanco J-F., Guerin C., Raoul Y., Mouloungui Z.: From petrochemical polyurethanes to biobased polyhydroxyurethanes. Macromolecules, 46, 3771-3792 (2013).

https://doi.org/10.1021/ma400197c

[2] Lligadas G., Ronda J. C., Galiá M., Cádiz V.: Plant oils as platform chemicals for polyurethane synthesis: Current state-of-the-art. Biomacromolecules, 11, 2825-2835 (2010).

https://doi.org/10.1021/bm100839x

[3] Das S., Pandey P., Mohanty S., Nayak S. K.: Insight on castor oil based polyurethane and nanocomposites: Recent trends and development. Polymer-Plastics Technology and Engineering, 56, 1556-1585 (2017). https://doi.org/10.1080/03602559.2017.1280685

[4] Zlatanić A., Lava C., Zhang W., Petrović Z. S.: Effect of structure on properties of polyols and polyurethanes based on different vegetable oils. Journal of Applied Polymer Science, 42, 809-819 (2004). https://doi.org/10.1002/polb.10737 
[5] Kong X., Liu G., Curtis J. M.: Novel polyurethane produced from canola oil based poly(ether ester) polyols: Synthesis, characterization and properties. European Polymer Journal, 48, 2097-2106 (2012).

https://doi.org/10.1016/j.eurpolymj.2012.08.012

[6] Gama N. V., Ferreira A., Barros-Timmons A.: Polyurethane foams: Past, present, and future. Materials, 11, 1841/1-1841/35 (2018)

https://doi.org/10.3390/ma11101841

[7] Wang C., Zheng Y., Xie Y., Qiao K., Sun Y., Yue L.: Synthesis of bio-castor oil polyurethane flexible foams and the influence of biotic component on their performance. Journal of Polymer Research, 22, 145/1-145/9 (2015).

https://doi.org/10.1007/s10965-015-0782-7

[8] Narine S. S., Kong X., Bouzidi L., Sporns P.: Physical properties of polyurethanes produced from polyols from seed oils: II. Foams. Journal of the American Oil Chemists Society, 84, 65-72 (2007).

https://doi.org/10.1007/s11746-006-1008-2

[9] Stirna U., Lazdiña B., Vilsone D., Lopez M. J., VargasGarcía M. C., Suárez-Estrella F., Moreno J.: Structure and properties of the polyurethane and polyurethane foam synthesized from castor oil polyols. Journal of Cellular Plastics, 48, 476-488 (2012). https://doi.org/10.1177/0021955X12445178

[10] Guo A., Javni I., Petrovic Z.: Rigid polyurethane foams based on soybean oil. Journal of Applied Polymer Science, 77, 467-473 (2000).

https://doi.org/10.1002/(SICI)10974628(20000711)77:2<467::AID-APP25>3.0.CO;2-F

[11] Hu Y. H., Gao Y., Wang D. N., Hu C. P., Zu S., Vanoverloop L., Randall D.: Rigid polyurethane foam prepared from a rape seed oil based polyol. Journal of Applied Polymer Science, 84, 591-597 (2002).

https://doi.org/10.1002/app.10311

[12] Gu R., Konar S., Sain M.: Preparation and characterization of sustainable polyurethane foams from soybean oils. Journal of the American Oil Chemists Society, 89, 2103-2111 (2012).

https://doi.org/10.1007/s11746-012-2109-8

[13] Zhang C., Kessler M. R.: Bio-based polyurethane foam made from compatible blends of vegetable-oil-based polyol and petroleum-based polyol. ACS Sustainable Chemistry and Engineering, 3, 743-749 (2015) https://doi.org/10.1021/acssuschemeng.5b00049

[14] Kim M. W., Kwon S. H., Park H., Kim B. K.: Glass fiber and silica reinforced rigid polyurethane foams. Express Polymer Letters, 11, 374-382 (2017). https://doi.org/10.3144/expresspolymlett.2017.36

[15] Adnan S., Tuan Ismail T. N. M., Mohd Noor N., Din N. S. M. N. M., Hanzah N. A., Shoot Kian Y., Abu Hassan H.: Development of flexible polyurethane nanostructured biocomposite foams derived from palm oleinbased polyol. Advances in Materials Science and Engineering, 2016, 4316424/1-4316424/12 (2016). https://doi.org/10.1155/2016/4316424
[16] Chen L., Rende D., Schadler L. S., Ozisik R.: Polymer nanocomposite foams. Journal of Material Chemistry A, 1, 3837-3850 (2013) https://doi.org/10.1039/C2TA00086E

[17] Pauzi N. N. P. N., Majid R. A., Dzulkifli M. H., Yahya M. Y.: Development of rigid bio-based polyurethane foam reinforced with nanoclay. Composites Part B: Engineering, 67, 521-526 (2014).

https://doi.org/10.1016/j.compositesb.2014.08.004

[18] Panda S. S., Samal S. K., Mohanty S., Nayak S. K.: Preparation, characterization, and properties of castor oil-based flexible polyurethane/Cloisite 30B nanocomposites foam. Journal of Composite Materials, 52, 531542 (2018).

https://doi.org/10.1177/0021998317710707

[19] Malewska E., Prociak A.: The effect of nanosilica filler on the foaming process and properties of flexible polyurethane foams obtained with rapeseed oil-based polyol. Polimery, 2015, 472-479 (2015).

https://doi.org/10.14314/polimery.2015.472

[20] Agrawal A., Kaur R., Walia R. S.: Development of vegetable oil-based conducting rigid PU foam. e-Polymers, 19, 411-420 (2019).

https://doi.org/10.1515/epoly-2019-0042

[21] Luo X., Yu Z., Cai Y., Wu Q., Zeng J.: Facile fabrication of environmentally-friendly hydroxyl-functionalized multiwalled carbon nanotubes/soy oil-based polyurethane nanocomposite bioplastics with enhanced mechanical, thermal, and electrical conductivity properties. Polymers, 11, 763/1-763/12 (2019).

https://doi.org/10.3390/polym11050763

[22] Habibi Y., Lucia L. A., Rojas O. J.: Cellulose nanocrystals: Chemistry, self-assembly, and applications. Chemical Reviews, 110, 3479-3500 (2010).

https://doi.org/10.1021/cr900339w

[23] Dufresne A.: Cellulose nanomaterials as green nanoreinforcements for polymer nanocomposites. Philosophical Transactions of the Royal Society A: Mathematical Physical and Engineering Sciences, 376, 20170040/120170040/23 (2018).

https://doi.org/10.1098/rsta.2017.0040

[24] Stepvani A. A., Evans D. A. C., Martin D. J., Annamalai P. K.: Hybrid polyether-palm oil polyester polyol based rigid polyurethane foam reinforced with cellulose nanocrystal. Industrial Crops and Products, 112, 378388 (2018).

https://doi.org/10.1016/j.indcrop.2017.12.032

[25] Huang X., De Hoop C. F., Xie J., Wu Q., Boldor D., Qi J.: High bio-content polyurethane (PU) foam made from bio-polyol and cellulose nanocrystals (CNCs) via microwave liquefaction. Materials and Design, 138, 1120 (2018).

https://doi.org/10.1016/j.matdes.2017.10.058

[26] Li Y., Ren H., Ragauskas A. J.: Rigid polyurethane foam reinforced with cellulose whiskers: Synthesis and characterization. Nano-Micro Letters, 2, 89-94 (2010). https://doi.org/10.1007/BF03353624 
[27] Li Y., Ren H., Ragauskas A. J.: Rigid polyurethane foam/cellulose whisker nanocomposites: Preparation, characterization, and properties. Journal of Nanoscience and Nanotechnology, 11, 6904-6911 (2010). https://doi.org/10.1166/jnn.2011.3834

[28] Cordero A. I., Amalvy J. I., Fortunati E., Kenny J. M., Chiacchiarelli L. M.: The role of nanocrystalline cellulose on the microstructure of foamed castor-oil polyurethane nanocomposites. Carbohydrate Polymers, 134, $110-118$ (2015).

https://doi.org/10.1016/j.carbpol.2015.07.077

[29] Zhou X., Sain M. M., Oksman K.: Semi-rigid biopolyurethane foams based on palm-oil polyol and reinforced with cellulose nanocrystals. Composites Part A: Applied Science and Manufacturing, 83, 56-62 (2016). https://doi.org/10.1016/j.compositesa.2015.06.008

[30] Ugarte L., Santamaria-Echart A., Mastel S., Autore M., Hillendbrand R., Corcuera M. A., Eceiza A.: An alternative approach for the incorporation of cellulose nanocrystals in flexible polyurethane foams based on renewably sourced polyols. Industrial Crops and Products, 95, 564-573 (2017).

https://doi.org/10.1016/j.indcrop.2016.11.011

[31] Corsello F. A., Bolla P. A., Anbinder P. S., Serradell M. A., Amalvy J. I., Peruzzo P. J.: Morphology and properties of neutralized chitosan-cellulose nanocrystals biocomposite films. Carbohydrate Polymers, 156, 452 459 (2017).

https://doi.org/10.1016/j.carbpol.2016.09.031

[32] Reid M. S., Villalobos M., Cranston E. D.: Benchmarking cellulose nanocrystals: From the laboratory to industrial production. Langmuir, 337, 1583-1598 (2017). https://doi.org/10.1021/acs.langmuir.6b03765

[33] Espinoza Pérez J. D., Haagenson D. M., Pryor S. W., Ulven C. A., Wiesenborn D. P.: Production and characterization of epoxidized canola oil. Transactions of the ASABE, 52, 1289-1297 (2009).

https://doi.org/10.13031/2013.27772

[34] Chen J., Soucek M. D., Simonsick W. J., Celikay R. W.: Epoxidation of partially norbornylized linseed oil. Macromolecular Chemistry and Physics, 203, 2042 2057 (2002).

https://doi.org/10.1002/1521-

3935(200210)203:14<2042::AID-MACP2042>3.0.CO;2-0

[35] Vlček T., Petrović Z. S.: Optimization of the chemoenzymatic epoxidation of soybean oil. Journal of the American Oil Chemists' Society, 83, 247-252 (2006). https://doi.org/10.1007/s11746-006-1200-4

[36] Mosiewicki M. A., Rojek P., Michałowski S., Aranguren M. I., Prociak A.: Rapeseed oil-based polyurethane foams modified with glycerol and cellulose micro/ nanocrystals. Journal of Applied Polymer Science, 132, 41602/1-41602/8 (2015).

https://doi.org/10.1002/app.41602
[37] Gómez-Ordóñez E., Rupérez P.: FTIR-ATR spectroscopy as a tool for polysaccharide identification in edible brown and red seaweeds. Food Hydrocolloids, 25, 1514-1520 (2011). https://doi.org/10.1016/j.foodhyd.2011.02.009

[38] Mandal A., Chakrabarty D.: Isolation of nanocellulose from waste sugarcane bagasse (SCB) and its characterization. Carbohydrate Polymers, 86, 1291-1299 (2011). https://doi.org/10.1016/j.carbpol.2011.06.030

[39] Parada Hernandez N. L., Bonon A. J., Bahú J. O., Barbosa M. I. R., Maciel M. R. W, Maciel Filho R.: Epoxy monomers obtained from castor oil using a toxicity-free catalytic system. Journal of Molecular Catalysis A: Chemical, 426, 550-556 (2017).

https://doi.org/10.1016/j.molcata.2016.08.005

[40] Petrović Z. S., Zavargo Z., Flynn J. H., Macknight W. J.: Thermal degradation of segmented polyurethanes. Journal of Applied Polymer Science, 51, 1087-1095 (1994). https://doi.org/10.1002/app.1994.070510615

[41] Aoyagi Y., Yamashita K., Doi Y.: Thermal degradation of poly[(R)-3-hydroxybutyrate], poly[E-caprolactone], and poly[(S)-lactide]. Polymer Degradation and Stability, 76, 53-59 (2002).

https://doi.org/10.1016/S0141-3910(01)00265-8

[42] Chrissafis K., Paraskevopoulos K. M., Bikiaris D. N.: Thermal degradation kinetics of the biodegradable aliphatic polyester, poly(propylene succinate). Polymer Degradation and Stability, 91, 60-68 (2006). https://doi.org/10.1016/j.polymdegradstab.2005.04.028

[43] Kong X., Narine S. S.: Physical properties of polyurethane plastic sheets produced from polyols from canola oil. Biomacromolecules, 8, 2203-2209 (2007). https://doi.org/10.1021/bm070016i

[44] Eychenne V., Mouloungui Z., Gaset A.: Thermal behavior of neopentylpolyol esters: Comparison between determination by TGA-DTA and flash point. Thermochimica Acta, 320, 201-208 (1998). https://doi.org/10.1016/S0040-6031(98)00466-3

[45] Lin B., Yang L., Dai H., Hou Q., Zhang L.: Thermal analysis of soybean oil based polyols. Journal of Thermal Analysis and Calorimetry, 95, 977-983 (2009). https://doi.org/10.1007/s10973-007-8929-3

[46] dos Santos Politi J. R., de Matos P. R. R., Araújo Sales M. J.: Comparative study of the oxidative and thermal stability of vegetable oils to be used as lubricant bases. Journal of Thermal Analysis and Calorimetry, 111, 1437-1442 (2013). https://doi.org/10.1007/s10973-012-2529-6

[47] Cao X., Habibi Y., Lucia L. A.: One-pot polymerization, surface grafting, and processing of waterborne polyurethane-cellulose nanocrystal nanocomposites. Journal of Material Chemistry, 19, 7137-7145 (2009). https://doi.org/10.1039/B910517D

[48] Celebi H., Kurt A.: Effects of processing on the properties of chitosan/cellulose nanocrystal films. Carbohydrate Polymers, 133, 284-293 (2015). https://doi.org/10.1016/j.carbpol.2015.07.007 
[49] Yeganeh H., Hojati-Talemi P.: Preparation and properties of novel biodegradable polyurethane networks based on castor oil and poly(ethylene glycol). Polymer Degradation and Stability, 92, 480-489 (2007). https://doi.org/10.1016/j.polymdegradstab.2006.10.011

[50] Ramakrishna S., Huang Z-M.: Biocomposites. Comprehensive Structural Integrity, 9, 215-296 (2003). https://doi.org/10.1016/B978-0-12-803581-8.00965-6

[51] Kong X., Liu G., Qi H., Curtis J. M.: Preparation and characterization of high-solid polyurethane coating systems based on vegetable oil derived polyols. Progress in Organic Coatings, 76, 1151-1160 (2013).

https://doi.org/10.1016/j.porgcoat.2013.03.019
[52] Shahrousvand E., Shahrousvand M., Ghollasi M., Seyedjafari E., Jouibari I. S., Babaei A., Salimi A.: Preparation and evaluation of polyurethane/cellulose nanowhisker bimodal foam nanocomposites for osteogenic differentiation of hMSCs. Carbohydrate Polymers, 171, 281-291 (2017).

https://doi.org/10.1016/j.carbpol.2017.05.027 